\title{
Verrucous Carcinoma of the Esophagus
}

\author{
Ryo Ogawa $^{1}$, Jun Nishikawa ${ }^{2}$, Tadatoshi Kakimoto ${ }^{3}$ and Isao Sakaida ${ }^{1}$
}

Key words: verrucous carcinoma, hyperkeratinization, esophagus

(Intern Med 55: 3219-3220, 2016)

(DOI: 10.2169/internalmedicine.55.7206)

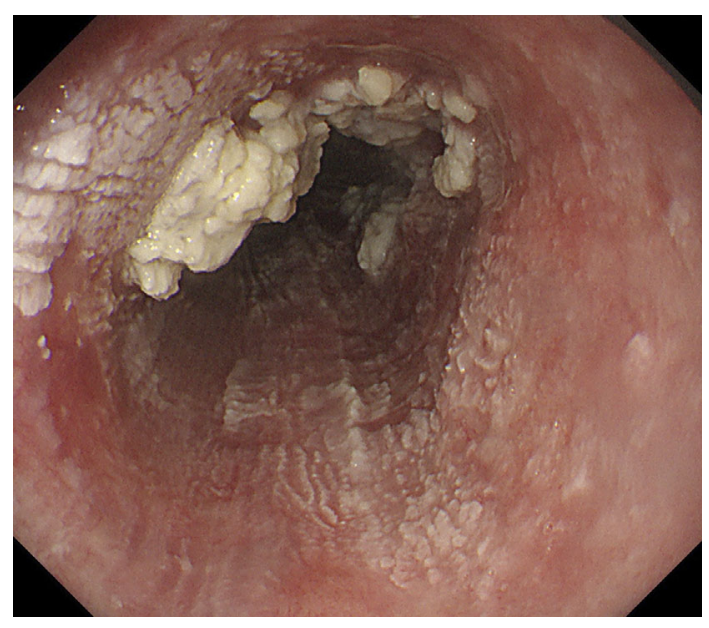

Picture 1.

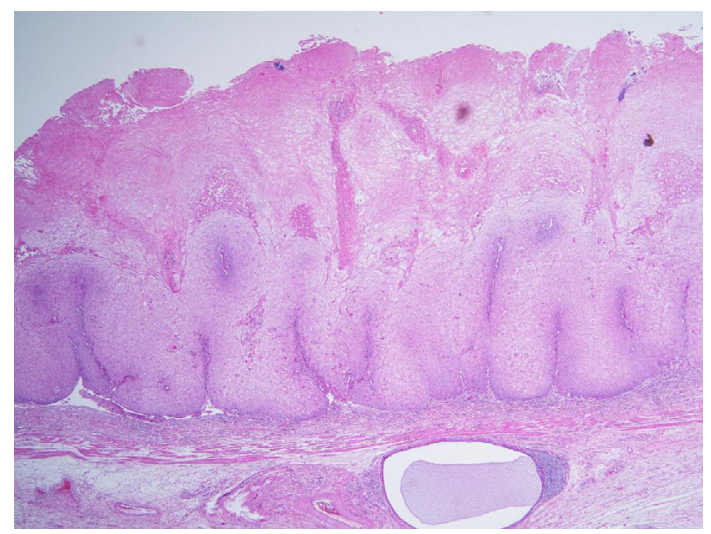

Picture 3.

A 77-year-old man with a chief complaint of dysphasia underwent esophagogastroduodenoscopy (EGD). We found a whitish warty mucosa and a cauliflower-like mass in the middle esophagus (Picture 1). The whitish fluffy lesion extended to the lower esophagus. The presence of irregularly

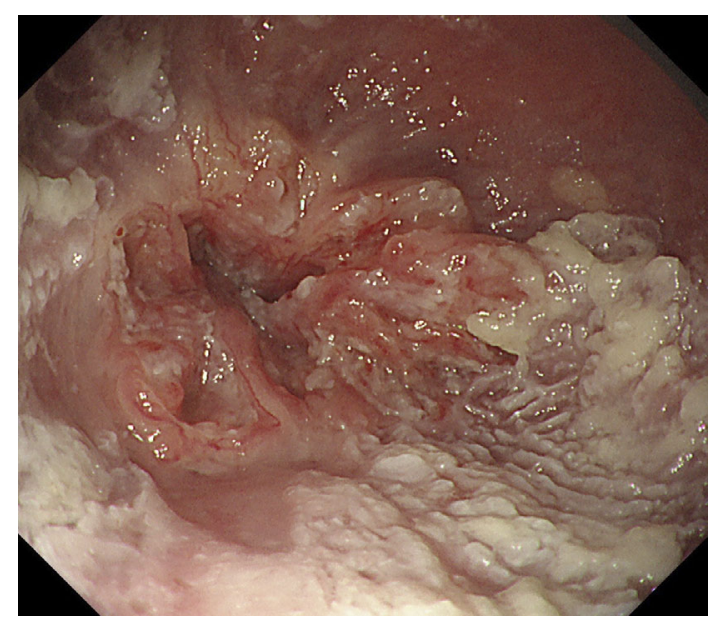

Picture 2.

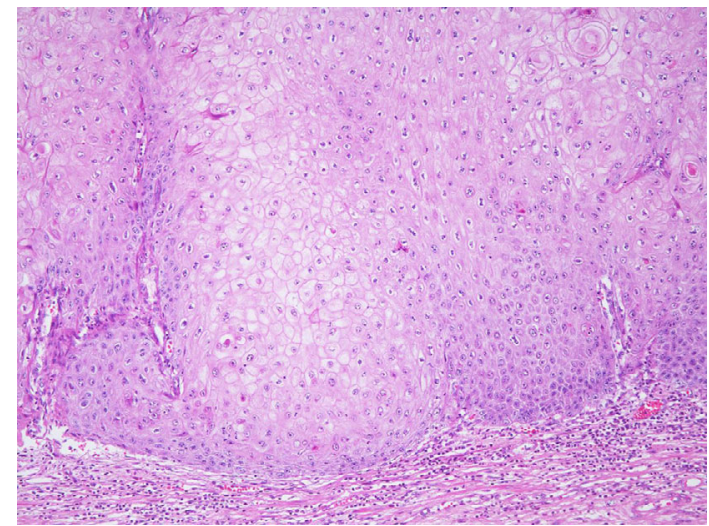

Picture 4.

${ }^{1}$ Department of Gastroenterology and Hepatology, Yamaguchi University Graduate School of Medicine, Japan, ${ }^{2}$ Department of Laboratory Science, Yamaguchi University Graduate School of Medicine, Japan and ${ }^{3}$ Department of Surgery, Hofu Institute of Gastroenterology, Japan Received for publication January 28, 2016; Accepted for publication March 1, 2016 Correspondence to Dr. Jun Nishikawa, junnis @ yamaguchi-u.ac.jp 
The mucosal surface, except for the area at the esophagogastric junction, consisted of keratinizing squamous epithelium with minimal cellular atypia, which was limited to the mucosal layer (Picture 3,4), and a diagnosis of verrucous carcinoma was made.

Verrucous carcinoma of the esophagus is extremely rare. For patients who show verrucous whitish protrusions in the esophagus on EGD, verrucous carcinoma should therefore be considered in the differential diagnosis. Multiple biopsies are recommended to confirm the diagnosis of verrucous carcinoma $(1,2)$.

The authors state that they have no Conflict of Interest (COI).

\section{References}

1. Tajiri $\mathrm{H}$, Muto M, Boku N, Ohtsu A, Yoshida S, Kawahara H. Verrucous carcinoma of the esophagus completely resected by endoscopy. Am J Gastroenterol 95: 1076-1077, 2000.

2. Ramani C, Shah N, Nathan RS. Verrucous carcinoma of the esophagus: A case report and literature review. World J Clin Cases 2: 284-288, 2014.

The Internal Medicine is an Open Access article distributed under the Creative Commons Attribution-NonCommercial-NoDerivatives 4.0 International License. To view the details of this license, please visit (https://creativecommons.org/licenses/ by-nc-nd/4.0/).

(C) 2016 The Japanese Society of Internal Medicine http://www.naika.or.jp/imonline/index.html 